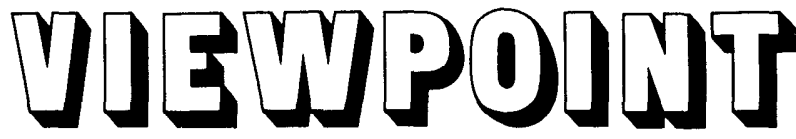

\section{Grazing Management Terminology}

In order to communicate ideas one needs a set of terms with clear and precise meanings. Grazing management terminology has been confusing ever since Jared Smith recommended the regular deferment of grazing to improve and maintain range condition. Heady $(1970)^{1}$ in a review of grazing system terms stated: "The term used to label a system seldom defines the design of that system.-Therefore, a

'Heady, Harold F. 1970. Grazing Systems: Terms and Definitions. J. Range Manage. 23:59-61. writer or a speaker cannot be fully understood unless he describes his system in more detail than simply naming it." It is my purpose to define a set of terms applying to grazing management and to present a procedure for nomenclature of grazing systems that will aid in defining the design of the system.

Grazing management is a broad term which may be defined as: The manipulation of livestock grazing to accomplish a desired result. As such, grazing management may include practices such as deferred grazing or use of a grazing system. A grazing manage- ment plan is a program of action designed to secure the best practicable use of the forage resources.

There are several terms used to describe types of grazing management which need precise definitions. Several other terms should be dropped because they cannot be precisely defined. Those terms which need defining are continuous grazing, intermittent grazing, deferred grazing, grazing system, and rotational grazing. Most confusion arises from the nomenclature of grazing systems with alternate periods of grazing and rest. The definitions proposed are as follows: 
Continuous grazing. The grazing of a specific unit by livestock throughout a year or grazing season. The term is not necessarily synonymous with yearlong grazing.

Intermittent grazing. Grazing rangcland or tame pastureland for indefinite periods at irregular intervals.

Deferred grazing. The use of deferment in the grazing management of a unit, but not in a systematic rotation including other units.

Grazing system. A specialization of grazing management which defines systematically recurring periods of grazing and deferment for two or more pastures or management units.

Rotational grazing. A form of grazing management generally used on tame pasture or cropland pasture, which ernbraces periods of heavy stocking followed by periods of rest for herbage recovery during the same season.

Properly used, these terms should provide adequate classification of grazing management practices. Attempts to attach very restricted meanings to common words such as "rest" and "ungrazed" only lead to greater confusion. If there is a real need for more specific terms to describe grazing management practices, coining new terms would be better than trying to attach a restricted meaning to a common word.

While the terms defined separate the primary types of grazing management, they do not assist in defining the design of specific grazing systems. To aid in this problem, the following system of nomenclature is proposed. It is intended to be used in much the same manner as scientific names of plants or diagnostic horizons in soil classification. It is recommended that specific individual common names be developed for those grazing systems that are used significantly. However, all grazing systems should be referenced in publication with the specific numerical designation describing the system.

The system of nomenclature shall consist of a numerical description of the four primary factors (number of pastures, number of herds, length of grazing periods, length of rest periods) involved in any grazing system in the following order: [ the number of pastures (or management units); number of herds; length of grazing periods; length of deferment periods for any given management unit in the system followed by an abbreviation of the unit of time used]. Examples:

1. Merrill system [4-3;12:4 mo.] is a grazing system with 4 pastures, 3 herds of livestock, a 12-month grazing period and a 4-month deferment period.

2. South African switchback
[2-1,3:3,6:3,3:6 mo.] is a grazing system with 2 pastures, 1 herd, and a grazing cycle of 3 months grazing, 3 months deferment, 6 months grazing, 3 months deferment, 3 months grazing, 6 months deferment.

3. [14-1;12:156 da.] A grazing system consisting of 14 pastures, 1 herd, a 12-day grazing period and a 156-day deferment period.

Grazing systems having more than one herd in which the herds are rotated on different schedules and the rest periods differ among pastures should be described in more detail. In such cases, the sequence of grazing and rest must be given for each pasture, and the rotation sequence described for each herd.

Terms which frequently contribute confusion to the range vocabulary include deferred-rotation, rotationdeferred, rest-rotation, decision deferment, non-selective grazing, short duration grazing, high-intensity, lowfrequency (HILF), and other terms which are not applicable to any particular grazing system but generally refer to a category of systems. Use of these terms frequently leads to the problem pointed out by Heady (1970). That is, they do not specifically describe the system, and adequate explanation is not included. Some of these terms have a place in the range vocabulary, but they need clarification.

Distinction may be made between types of systems based upon the proportion of time for rest and for grazing during the cycle for a pasture. The stocking density index may be used as a measure to make this distinction. Grazing systems having an index number $>1$ and $\leqslant 2$ fall into the conventional category of deferred-rotation as defined by Sampson $(1951)^{2}$. Other terms which have been used to describe such systems include restrotation, rotation-deferred, rotational deferment, rotational grazing, and rotational resting. Past attempts to attach more specific meanings to these terms generally have not been successful. It is recommended that deferredrotation be the preferred term for reference to this general group of grazing systems and that when the writer is referring to any particular system it should be identified with the proper numerical description.

Grazing systems having a stocking density index of $>2$ fall into the group generally referred to as short duration, non-selective, intensive, or highintensity, low-frequency. The history of these grazing systems is much shorter and there has not been as great

\footnotetext{
${ }^{2}$ Sampson, Arthur W. 1951. A Symposium on Rotation Grazing in North America. J Range Manage. 4:19-24.
}

a proliferation of descriptive terms as for those classed as deferred-rotation systems. While there is a great deal of variation among systems which can be classed as short duration grazing systems, there does not appear to be a need for additional terms. Short duration systems were initially developed in South Africa and Rhodesia. Although they have been termed "non-selective grazing systems," it would seem desirable to restrict the use of non-selective grazing to describing the type of utilization which may occur. Short duration would refer to the type of grazing system which might or might not produce nonselective grazing.

There remains a large area of grazing management which has not been clearly defined. This includes all of those management systems which utilize intermittent grazing and deferment, but depend upon the operator's judgment and not a predetermined schedule. This type of management can be very effective in improving or maintaining range condition but does not lend itself to any system of nomenclature other than grazing management. When reported in the literature, care should be taken to outline the criteria or guidelines used by the operator in determining stocking rates and grazing and rest periods.

\section{Definitions of Terms Used}

Deferment-Delay or discontinuance of livestock grazing on an area for an adequate time to provide for plant reproduction, establishment of new plants, or restoration of vigor of existing plants.

Deferred-rotation grazing-Any grazing system having a stocking density index $>1$ and $\leqslant 2$, which provides for a systematic rotation of the deferment among pastures.

Grazing period The length of time that livestock are grazed on a specific area.

Non-selective grazing-Utilization of forage by grazing animals in such a way that all forage species and plants are grazed to a comparable degree. It is generally achieved by using a high stocking density for a short grazing period. In practice this can rarely be achieved; however, the concept is useful.

Rest period-A time interval during which a pasture is ungrazed by livestock.

Short duration grazing-Any grazing system having a stocking density index $>2$.

Stocking density-The relationship between the number of animals and area of land at any instant of time. It may be expressed as animal-units/acre, animal-units/section, or animal-unit months/acre.

Stocking density index-The reciprocal of that fraction of land available to the animals for the entire grazable period which is being grazed at any one time.

- M. M. Kothmam, Texas A \& M University, College Station, Texas. 